\title{
ОСЛОЖНЕНИЯ ПОЗДНЕГО ПОСЛЕОПЕРАЦИОННОГО ПЕРИОДА ПОСЛЕ ДРЕНАЖНОЙ ХИРУРГИИ ВТОРИЧНОЙ НЕОВАСКУЛЯРНОЙ ГЛАУКОМЫ (ПЯТНАДЦАТИЛЕТНИЙ ОПЫТ)
}

\author{
'Билецкая В.А., 1,2Липатов Д.В., 'Фролов М.А. \\ ФГАОУ ВО «Российский Университет Дружбы Народов», Москва \\ ФГБУ Национальный Медицинский Исследовательский Центр Эндокринологии Минздрава России, Москва
}

\begin{abstract}
АКТУАЛЬНОСТЬ: неоваскулярная глаукома (НГ) является важной и актуальной проблемой в современном обществе. В настоящее время НГ и ее осложнения остаются одними из основных причин потери зрения у пациентов с сахарным диабетом (СД) и пролиферативной диабетической ретинопатией (ДР). Это заболевание приводит к необратимой слепоте в 25 раз чаще, чем в общей популяции. Более чем $10 \%$ пациентов становятся инвалидами по зрению.
\end{abstract}

ЦЕЛЬ РАБОТЫ - оценить отдаленные результаты дренажной хирургии при диабетической НГ, проанализировать количество и качество осложнений в позднем послеоперационном периоде.

МАТЕРИАЛЫ И МЕТОДЫ: за период 2005-2019 гг. в отделении диабетической ретинопатии и офтальмохирургии клиники ФГБУ «НМИЦ Эндокринологии» МЗ России были прооперированы 138 пациентов (141 глаз) с НГ, средний возраст которых составил 67.9 3.2 лет, продолжительность диабета - $16.1 \pm 4.7$ лет,

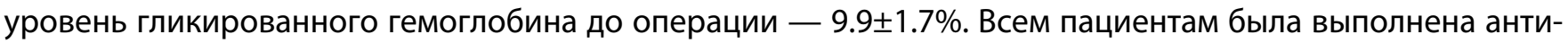
глаукомная дренирующая операция с имплантацией клапанов Ахмеда (127 глаза) и Мольтено (14 глаз). Статистические данные по пациентам с дренажом Мольтено в учет не принимались из-за статистической недостоверности результатов (малое число пациентов).

PЕЗУЛЬTАТЫ: у всех пациентов (100\%) в послеоперационном периоде был купирован болевой синдром и в 107 случаях (77\%) получено стойкое снижение внутриглазного давления. В 4 случаях (3\%) была получена стойкая гипотония глазного яблока из-за цилиохориоидальной отслойки, которая была купирована медикаментозными средствами. В оставшихся 28 случаях (20\%) ВГД не было компенсировано и оставалось повышенным (но не превышало 35 мм рт.ст.), что потребовало установку дополнительного клапана (2 случая), назначения комбинированной медикаментозной терапии (5 пациентов) и выполнения контактной транссклеральной диод-лазерной циклокоагуляции (КТДЛЦ) - 21 пациент.

В раннем п/о периоде отмечались: гифема (24\%), катаракта (7\%), мелкая передняя камера (4\%), закупорка дренажа (3\%) и цилиохориоидальная отслойка (1\%). В позднем п/о периоде были диагностированы: захват радужки (2\%), обнажение дренажной трубки (2\%), сосудистое бельмо роговицы (8\%) и эпителиально-эндотелиальная дистрофия роговицы (9\%).

ВЫВоды: несмотря на наличие осложнений, дренажная хирургия диабетической глаукомы у пациентов с СД продолжает оставаться эффективным методом выбора хирургического лечения пациентов с некомпенсированной НГ. 